\title{
The impact of medication reviews conducted in primary care on hospital admissions and mortality - a randomized controlled trial
}

\author{
Veronica Milos Nymberg ( $\sim$ veronica.milos_nymberg@med.lu.se ) \\ Lunds Universitet https://orcid.org/0000-0002-3836-3048 \\ Cecilia Lenander \\ Lunds Universitet \\ Beata Borgström Bolmsjö \\ Lunds Universitet
}

\section{Research article}

Keywords: medication reviews, primary care, elderly, randomized controlled study, hospital admissions, mortality

Posted Date: July 18th, 2019

DOI: https://doi.org/10.21203/rs.2.11674/v1

License: (c) (7) This work is licensed under a Creative Commons Attribution 4.0 International License. Read Full License

Version of Record: A version of this preprint was published at Drug, Healthcare and Patient Safety on January 1st, 2021. See the published version at https://doi.org/10.2147/DHPS.S283708. 


\section{Abstract}

Background Drug-related problems among the elderly population are common and increasing. Multi-professional medication reviews (MR) have arisen as a method to optimize drug therapy for frail elderly patients. Research has not yet been able to show conclusive evidence of the effect of MRs on mortality or hospital admissions. Aim The aim of this study was to assess the impact of MRs' on hospital admissions and mortality after six and 12 months in a frail population of 369 patients in primary care in a randomized controlled study. Methods Patients were blindly randomized to an intervention group (receiving MRs) and a control group (receiving usual care). Descriptive data on mortality and hospital admissions at six and 12 months were collected. Survival analysis was performed for time to death and time to the first hospital admission within 12 months. Results Of the total number of 369 included patients, 182 were randomized to the intervention group and 187 to the control group. Most of the patients (75\%) were females and lived in nursing homes. At six months, 50 patients of the baseline population (27\%) in the control group had been admitted to hospital at least once, compared to 40 patients $(21 \%)$ in the intervention group. At 12 months, the percentage had increased to $70(37 \%)$ in the control group compared to $53(29 \%)$ in the intervention group. Compared to usual care, we found that MRs reduced the risk of hospital admissions within 12 months by $36 \%(\mathrm{HR}=0.64,95 \% \mathrm{Cl} 0.45-0.90)$, but found no difference on mortality $(\mathrm{HR}=1.12,95 \% \mathrm{Cl} 0.78-1.61)$ between the groups. Conclusion We suggest that MRs should be recommended in the care of frail elderly patients with expected benefits on hospital admissions.

\section{Background}

Drug-related problems (DRPs) and polypharmacy in the elderly population are common and increasing (1). Lack of a consistent drug list and low physician continuity are some of the reasons for drug-related problems and the need for emergency hospital contacts (1). Most of these problems can be avoided and multi-professional medication reviews have arisen as a method to optimize drug therapy for frail elderly patients $(2,3)$. Meanwhile, medication reviews (MR) have been questioned for their efficacy (4). Even if studies have shown that pharmacists recommendations are clinically relevant $(5,6)$, recent research has not been able to demonstrate an effect on mortality or hospital admissions; hence the conclusion that more evidence is needed $(7,8)$. Furthermore, a systematic review and meta-analysis of randomized controlled trials with short follow-up time ( $<3$ months) showed no effect on clinical outcomes or quality of life and the researchers argued that it should be considered to stop performing medication reviews as standard care (9). This conclusion is controversial as medication reviews are well-established in Sweden and Swedish authorities grant incentives and other funding on an annual basis to healthcare providers in order to optimize drug therapy among elderly patients (10). It is important to mention that the heterogeneity of study designs and outcomes is a problem while performing meta-analyses.

The model for MRs in primary care in southern Sweden with focus on elderly patients with multiple illnesses is well-studied and has been shown to reduce potentially inappropriate medications (PIMs) and consequences due to medication errors (11). The integrated approach with a pharmacist helping in the clinical routine had initially been developed in hospital care but has been adapted to primary care. MRs using this approach have now been conducted for the last 15 years, both in nursing homes and community-dwelling elderly patients in Sweden, with the goal to improve quality of medication use and patient safety.

This randomized controlled trial (RCT), which was performed in 2012, included 369 patients and showed that multiprofessional medication reviews conducted by teams including nurses, pharmacists and GPs had a lowering effect on the number of drugs as well as on the number of PIMs among elderly patients (12). The first results showed that two months after the medication reviews, both the number of patients with at least one PIM and the number of intervention patients having 10 or more drugs had decreased in the intervention group, while there were no statistically significant differences in the control patients. DRPs were identified in $93 \%$ of the 182 patients in the intervention group and $16 \%$ of the DRPs were related to PIMs. 
As we could show statistically significant benefits in the intervention group receiving MRs in the short follow-up time, we considered it important to study this further by focusing on mortality data and hospital admissions during a longer follow-up time of six and 12 months.

\section{Aim}

The aim of this study was to assess the impact of multi-professional MRs on hard outcomes, such as hospital admissions and mortality, at six and 12 months in elderly patients in primary care.

\section{Methods}

\section{Study setting and design}

Primary care in Skåne county, southern Sweden is provided by approximately 150 primary health care centers (PHCCs), both public and private. All public PHCCs were invited to participate in the study. Four pharmacists with extensive prior experience of performing MRs were recruited to the project and assigned to four different areas in Skåne county. Patients eligible for inclusion were users of the multi-dose drug dispensing (MDD) system aged 75 years or older, living in nursing homes or community dwelling with municipally provided home care. Patients were included in the study after they provided written consent directly or through relatives in cases of severe cognitive impairment.

\section{Intervention}

The pharmacists randomized patients blindly to the intervention or the control group using non-transparent closed envelopes and with a random number generator, stratified only for geographic area (12).

All patients had MDD, thus ensuring compliance to the drug therapy and the medication changes. The control group received usual care. For patients in the intervention group, the pharmacists performed a systematic MR without personal patient contact. The MR consisted of a structured assessment in three steps (13). First, a nurse conducted a specific symptom evaluation and health status check including blood pressure, pulse, weight, tendency to fall and confusion and other symptoms using a validated symptom assessment form (Phase-20) (14). Medication lists (MDD cards) were printed by the pharmacists who had received permission to access patients' EMR (electronic medical record) as well as the electronic MDD record. Drug-related problems and PIMs were identified using a structured manner (12).

The pharmacists' recommendations were documented in patients' EMRs and communicated to the physician in different ways, depending on the PHCC's routines and organization and consisted of team rounds, written contact, personal contact and telephone contact. The physician decided about medication changes and this was documented in the patient's EMR.

\section{Data collection}

We followed the intervention and control groups from the initial baseline population of 369 patients for 12 months. Primary outcome variables were differences in survival time and time to the first hospital admission between the groups at six and 12 months (Figure 1). Secondary outcomes were difference in number of deaths and difference in number of hospital admissions between the groups at six and 12 months. Data from the EMR and the regional patient database were collected using Swedish personal numbers thus assuring $100 \%$ data coverage.

\section{Data analysis}

Descriptive data for baseline characteristics as well as mortality and hospital admissions were performed. Kaplan-Meier analysis was used to estimate survival function with time to the first hospital admission and time to death as outcome events. Non-parametric Kaplan-Meier was chosen as the exact survival time and time to the first hospital admission for each patient were known. As some of the patients in the control group received MRs during the follow-up period; they were 
censored in the survival analysis. Furthermore, we used the log-rank test for equality across strata (i.e. control and intervention group). The proportionality assumption was tested ( $p$-value $<0.05)$, which is the main assumption of the Cox proportional hazard model to determine the relationship between covariate and survival time or time to hospital admission and to obtain hazard ratio (HR).

Data were analysed using SPSS version 25 (15).

\section{Results}

Of the 369 included patients, 182 were randomized to the intervention group and 187 to the control group. Most of the patients $(75 \%)$ were females and lived in nursing homes. Patient characteristics of the population at baseline are described in Table 1, with no significant observed differences in age, sex, living form and number of drugs between the intervention and control group.

There was no difference in number of deaths between the groups at six and 12 months (Figure 1). The survival analysis showed no differences in mortality between groups at 12 months $(p=0.551)$ with a $\mathrm{HR}=1.12,(95 \% \mathrm{Cl} 0.78-1.61)$.

At six months, 50 patients of the baseline population (27\%) in the control group had been admitted to hospital at least once, compared to 40 patients (21\%) in the intervention group. At 12 months the percentage had increased to $70(37 \%)$ in the control group compared to $53(29 \%)$ in the intervention group (Table 2 and Figure 2 ).

A survival analysis with Kaplan Meier curve showed a significant decrease $(p=0.012)$ in risk for the first hospital admission at 12 months between the intervention and control group (Figure 3). Patients were censored for death in the intervention group and for death or when receiving a MR in the control group, depending on which event occurred first. The Cox regression analysis showed that MRs reduced the risk of hospital admissions by $36 \%(\mathrm{HR}=0.64,95 \% \mathrm{Cl} 0.45-0.90)$ compared to usual care. The proportionality assumption was fulfilled.

\section{Discussion}

This study found that the patients in the intervention group had a lower risk for first hospital admission within 12 months after the MR compared to the patients in the control group. We found no difference in mortality rate between the groups.

The studied population was elderly individuals that had multimorbidity and polypharmacy. The intervention and the control group were similar concerning age, living form and number of drugs at baseline.

Adverse drug reactions account for a substantial amount of all hospital admissions (16-18), and many of these are preventable $(17,18)$. Previously published data from this RCT $(12)$ showed no difference in number of drugs or PIMs between the groups at baseline but a significantly lower number of drugs and PIMs in the intervention group at two months follow-up, which indicates that MRs might reduce the occurrence of drug-related problems (DRPs). If DRPs can be prevented by reducing the number of drugs and PIMs through MRs, some hospital admissions could be avoided or delayed, and thereby could save both burden and costs for the individual patient as well as for the society.

Many studies of MRs are based on a patient population already admitted to the hospital and have shown that MRs in a hospital setting will extend the time to readmission (19-21). A strength of this study was that the MRs were performed in primary care, and this is where patients spend most of their time. Therefore, we believe this is where the impact of an MR is most significant. We estimate the effect of the MR on direct patient outcomes such as hospital admissions, which is reliable data thanks to Swedish personal numbers.

Another strength of this study is the long follow-up time (12 months), which is rare in this kind of study, due to the high mortality rate among this frail group of elderly patients. The two most common intervention recommendations the pharmacist presented to the physician were withdrawal of drug therapy (30\%) and reduced dosage (28\%) (12). Many PIMs, as

Page $4 / 10$ 
long-acting benzodiazepines and tramadol, need a longer withdrawal period with an initial stepwise lowered dosage. The long follow-up period in the present study allowed a clinical effect of the medication withdrawal; this is a strength of this study.

Censoring the individuals in the control group, which had received a MR, when the survival analysis was performed is also a strength of the study.

A weakness of the study is the lack of information about the reason for hospital admissions or if the hospital admission was due to a DRP. Some of the hospital admissions could be assumed to be related to DRPs as the previous paper on the same population showed a high incidence of reported falls (29\%) and severe falls leading to hospital admissions (17\%) prior to baseline (12). A significant proportion (87\%) of the studied population had treatment with fall risk increasing drugs (FRIDs) (12). Thus, further analysis on the possible association between DRPs and hospital admissions needs to be performed.

We have not analyzed data on morbidity such as number of chronic conditions and/or cognitive impairment, and this is a limitation of the study. Given the similarities in the number of drugs both between groups and between patients in different living forms, we can only assume that there were similar levels of multimorbidity in the groups. We found a positive effect of MRs on the risk for hospital admissions. As it is not solely about avoiding hospital admission, the impact of MRs on quality of life would be interesting to assess as only a few studies have raised this important question $(7,22)$.

Our results showed that MRs had no effect on mortality or on time to death when the intervention group and control group were compared, which is in-line with other research $(4,23)$.

It has been argued that MRs are part of the physicians' professional responsibilities. However, the multi-professional approach with pharmacist and nurse involvement might bring different dimensions upon patients' medication list, giving additional attention to frail elderly in an over-burdened primary care.

About 90,000 individuals over the age of 65 live in nursing homes in Sweden. This number represents less than $5 \%$ of the population aged 65 years and older (24) and hence is the part of the elderly population needing most daily care. We suggest that frail elderly individuals should be treated with increased attention, including by conducting MRs, in order to avoid hospital admissions.

\section{Conclusion}

The results show that MRs can have a significant impact on the risk for hospital admissions but not on mortality rate. MRs should be considered in the care of frail elderly patients with expected benefits on avoiding hospital admissions.

\section{Abbreviations}

DRP Drug Related Problem

EMR Electronic Medical Record

FRIDs Fall Risk Increasing Drugs

GP General Practitioner

MDD Multidose Drug Dispensing

MR Medication Review

PHCC Primary Health Care Center

PIM Potentially Inappropriate Medication

Page 5/10 
RCT Randomized Controlled Trial

\section{Declarations}

\section{Ethics and consent to participate}

The study has been approved by the Regional Ethical Review Board in Lund (Reg. no. 2018/8). Patients were included in the study after they provided written consent directly or through relatives in cases of severe cognitive impairment. The study adheres to CONSORT guidelines.

\section{Consent to publish}

We have obtained informed and written consent to publish from all study participants, as required by the Regional Ethical regulations in Sweden.

\section{Availability of data and materials}

The datasets used during the current study are available from the corresponding author on reasonable request.

\section{Competing Interest}

The authors declare that they have no competing interests.

\section{Funding}

This study was funded by Lions Forskningsfond Skåne.

\section{Authors contributions}

VMN, CL and BBB participated in the study design and coordination. VMN and CL participated in data collection. VMN and BBB participated in statistical analysis. All authors drafted, reviewed and approved the final manuscript.

\section{Acknowledgements}

We are indebted to Patrick Reilly for his expertise and invaluable advice in editing the manuscript and Sara Larsson Lönn for statistical input.

\section{References}

1. Hajjar ER, Cafiero AC, Hanlon JT. Polypharmacy in elderly patients. The American journal of geriatric pharmacotherapy. 2007;5(4):345-51.

2. Brulhart MI, Wermeille JP. Multidisciplinary medication review: evaluation of a pharmaceutical care model for nursing homes. Int J Clin Pharm. 2011;33(3):549-57.

3. Hellstrom LM, Bondesson A, Hoglund P, Midlov P, Holmdahl L, Rickhag E, et al. Impact of the Lund Integrated Medicines Management (LIMM) model on medication appropriateness and drug-related hospital revisits. Eur J Clin Pharmacol. 2011.

4. Holland R, Desborough J, Goodyer L, Hall S, Wright D, Loke YK. Does pharmacist-led medication review help to reduce hospital admissions and deaths in older people? A systematic review and meta-analysis. British journal of clinical pharmacology. 2008;65(3):303-16.

5. Modig S, Holmdahl L, Bondesson A. Medication reviews in primary care in Sweden: importance of clinical pharmacists' recommendations on drug-related problems. Int J Clin Pharm. 2016;38(1):41-5. 
6. Lenander C, Bondesson A, Viberg N, Jakobsson U, Beckman A, Midlov P. Effects of an intervention (SAKLAK) on prescription of potentially inappropriate medication in elderly patients. Fam Pract. 2017;34(2):213-8.

7. Renaudin P, Boyer L, Esteve MA, Bertault-Peres P, Auquier P, Honore S. Do pharmacist-led medication reviews in hospitals help reduce hospital readmissions? A systematic review and meta-analysis. British journal of clinical pharmacology. 2016;82(6):1660-73.

8. Khalil H, Bell B, Chambers H, Sheikh A, Avery AJ. Professional, structural and organisational interventions in primary care for reducing medication errors. Cochrane Database Syst Rev. 2017;10:CD003942.

9. Huiskes VJ, Burger DM, van den Ende $\mathrm{CH}$, van den Bemt BJ. Effectiveness of medication review: a systematic review and meta-analysis of randomized controlled trials. BMC family practice. 2017;18(1):5.

10. Odesjo H, Anell A, Boman A, Fastbom J, Franzen S, Thorn J, et al. Pay for performance associated with increased volume of medication reviews but not with less inappropriate use of medications among the elderly - an observational study. Scand $\mathrm{J}$ Prim Health Care. 2017;35(3):271-8.

11. Midlov P, Deierborg E, Holmdahl L, Hoglund P, Eriksson T. Clinical outcomes from the use of Medication Report when elderly patients are discharged from hospital. Pharm World Sci. 2008;30(6):840-5.

12. Milos V, Rekman E, Bondesson A, Eriksson T, Jakobsson U, Westerlund T, et al. Improving the Quality of Pharmacotherapy in Elderly Primary Care Patients Through Medication Reviews: A Randomised Controlled Study. Drugs Aging. 2013;30(4):23546.

13. Hellstrom LM, Bondesson A, Hoglund P, Midlov P, Holmdahl L, Rickhag E, et al. Impact of the Lund Integrated Medicines Management (LIMM) model on medication appropriateness and drug-related hospital revisits. Eur J Clin Pharmacol. 2011;67(7):741-52.

14. Hedström M, Lidström B, Hulter-Åsberg K. PHASE-20: a new instrument for assessment of possible therapeutic drugrelated symptoms among elderly in nursing homes [in Swedish]. Nordic Journal of Nursing Research and Clinical Studies (Vård i Norden). 2009;4:9-14.

15. IBM Corp. IBM SPSS Statistics for Windows, Version 25.0. Armonk, NY2013.

16. Oscanoa TJ, Lizaraso F, Carvajal A. Hospital admissions due to adverse drug reactions in the elderly. A meta-analysis. Eur J Clin Pharmacol. 2017;73(6):759-70.

17. Davies EC, Green CF, Mottram DR, Rowe PH, Pirmohamed M. Emergency re-admissions to hospital due to adverse drug reactions within 1 year of the index admission. British journal of clinical pharmacology. 2010;70(5):749-55.

18. Pirmohamed M, James S, Meakin S, Green C, Scott AK, Walley TJ, et al. Adverse drug reactions as cause of admission to hospital: prospective analysis of 18820 patients. BMJ. 2004;329(7456):15-9.

19. Gillespie U, Alassaad A, Henrohn D, Garmo H, Hammarlund-Udenaes $M$, Toss $H$, et al. A comprehensive pharmacist intervention to reduce morbidity in patients 80 years or older: a randomized controlled trial. Arch Intern Med. 2009;169(9):894900.

20. Gustafsson M, Sjolander M, Pfister B, Jonsson J, Schneede J, Lovheim H. Pharmacist participation in hospital ward teams and hospital readmission rates among people with dementia: a randomized controlled trial. European Journal of Clinical Pharmacology. 2017;73(7):827-35.

21. Ravn-Nielsen LV, Duckert ML, Lund ML, Henriksen JP, Nielsen ML, Eriksen CS, et al. Effect of an In-Hospital Multifaceted Clinical Pharmacist Intervention on the Risk of Readmission: A Randomized Clinical Trial. JAMA Intern Med. 2018;178(3):375- 
82.

22. Lenander C, Elfsson B, Danielsson B, Midlov P, Hasselstrom J. Effects of a pharmacist-led structured medication review in primary care on drug-related problems and hospital admission rates: a randomized controlled trial. Scand J Prim Health Care. 2014;32(4):180-6.

23. Wallerstedt SM, Kindblom JM, Nylen K, Samuelsson O, Strandell A. Medication reviews for nursing home residents to reduce mortality and hospitalization: systematic review and meta-analysis. British journal of clinical pharmacology.

2014;78(3):488-97.

24. National Board of Health and Welfare. Statistics on Elderly and People with impairments - management form 2017.

Stockholm. In Swedish.

https://www.socialstyrelsen.se/statistik/statistikefteramne/socialtjanstinsatsertillaldreochpersonermedfunktionsnedsattning. Accesed on 11th March 2019.

\section{Tables}

Table 1. Population characteristics at baseline.

\begin{tabular}{|l|l|l|l|}
\hline \multirow{3}{*}{$\begin{array}{l}\text { All patients } \\
\mathrm{n}=369\end{array}$} & Baseline characteristics & $\begin{array}{l}\text { Intervention } \\
(\mathrm{n}=\mathbf{1 8 2})\end{array}$ & $\begin{array}{l}\text { Control } \\
(\mathrm{n}=187)\end{array}$ \\
\cline { 2 - 4 } & Female sex, n (\%) & $138(75.8)$ & $142(75.9)$ \\
\cline { 2 - 4 } & Institutionalized, n (\%) & $139(76.4)$ & $140(74.9)$ \\
\cline { 2 - 4 } & Age, mean & 87.0 & 87.7 \\
\cline { 2 - 4 } & No of drugs & $9.2(1-20)$ & $9.7(3-25)$ \\
\hline
\end{tabular}

Table 2. Number of hospital admissions.

\begin{tabular}{|c|c|c|c|c|}
\hline \multirow{2}{*}{ No of hospital admissions } & \multicolumn{2}{|l|}{ Within 6 months, no of patients } & \multicolumn{2}{l|}{ Within 12 months, no of patients } \\
\cline { 2 - 5 } & Intervention & Control & Intervention & Control \\
\hline 0 & & & & 129 \\
\hline 1 & 142 & 137 & 34 & 117 \\
\hline 2 & 30 & 35 & 11 & 44 \\
\hline$\geq 3$ & 8 & 13 & 8 & 8 \\
\hline
\end{tabular}

\section{Figures}




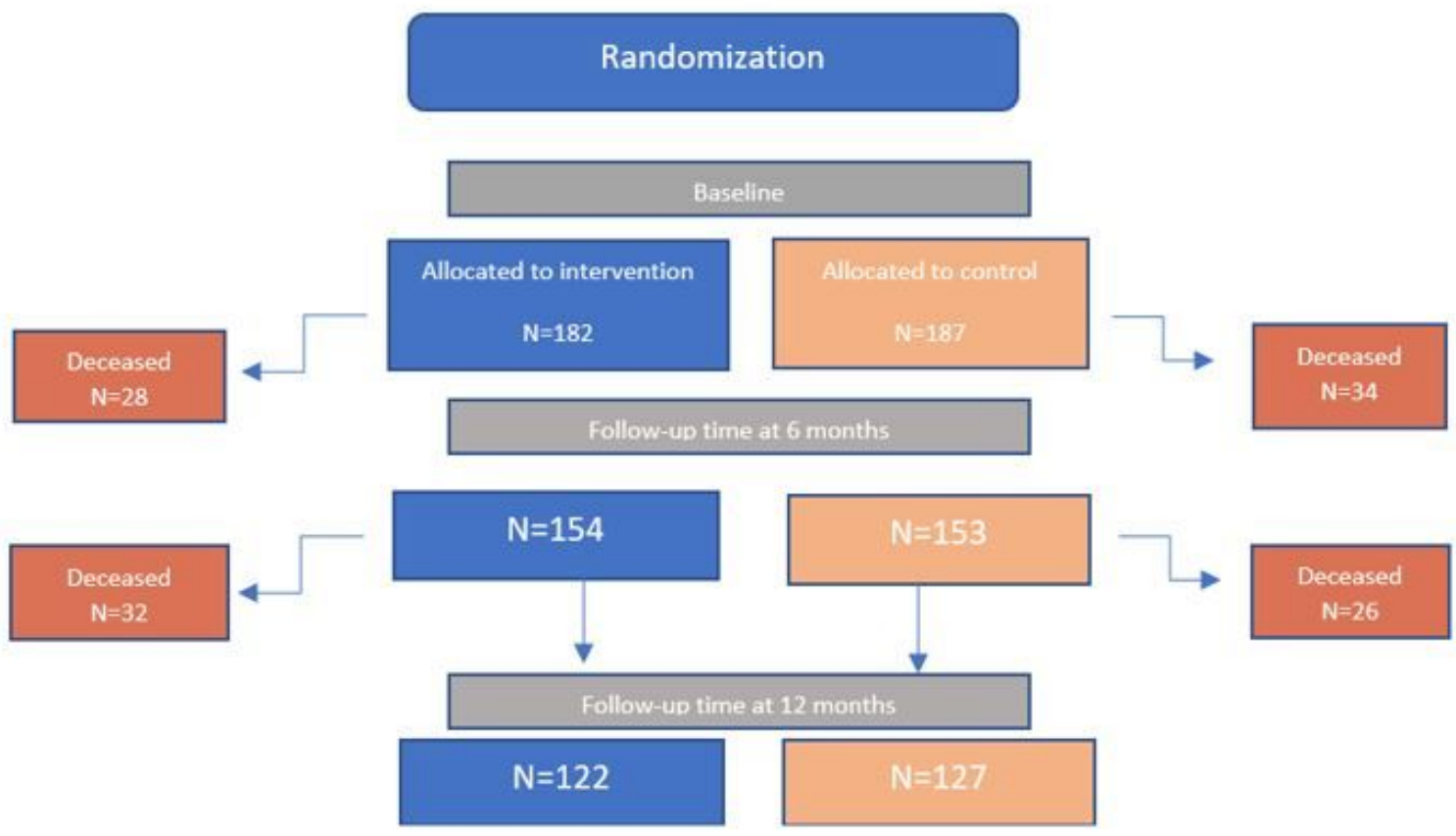

\section{Figure 1}

Flow chart for the studied population at baseline, six and 12 months.

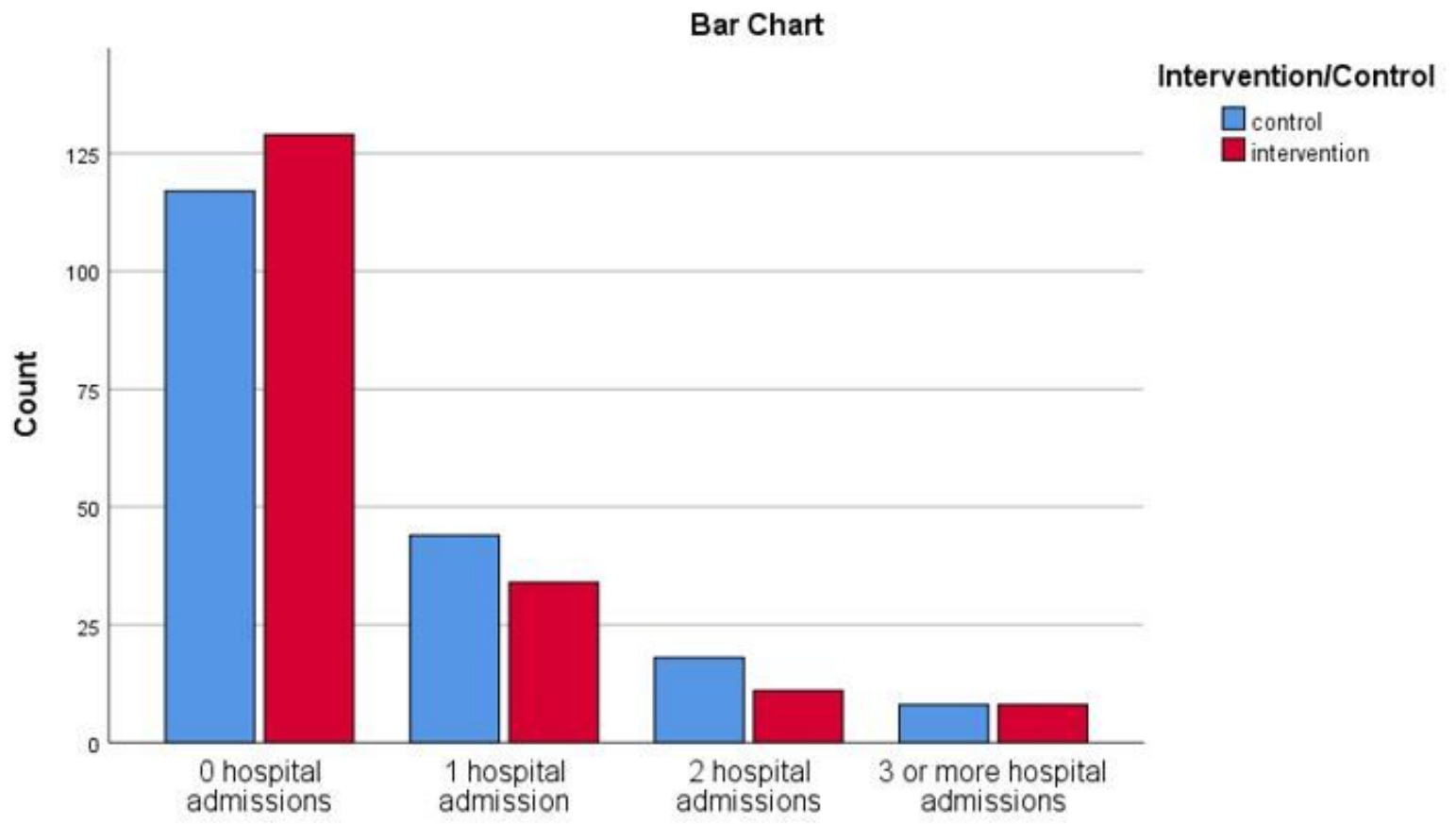

Number of hospital admissions within 12 months

\section{Figure 2}

Number of hospital admissions within 12 months in the control and intervention group. 


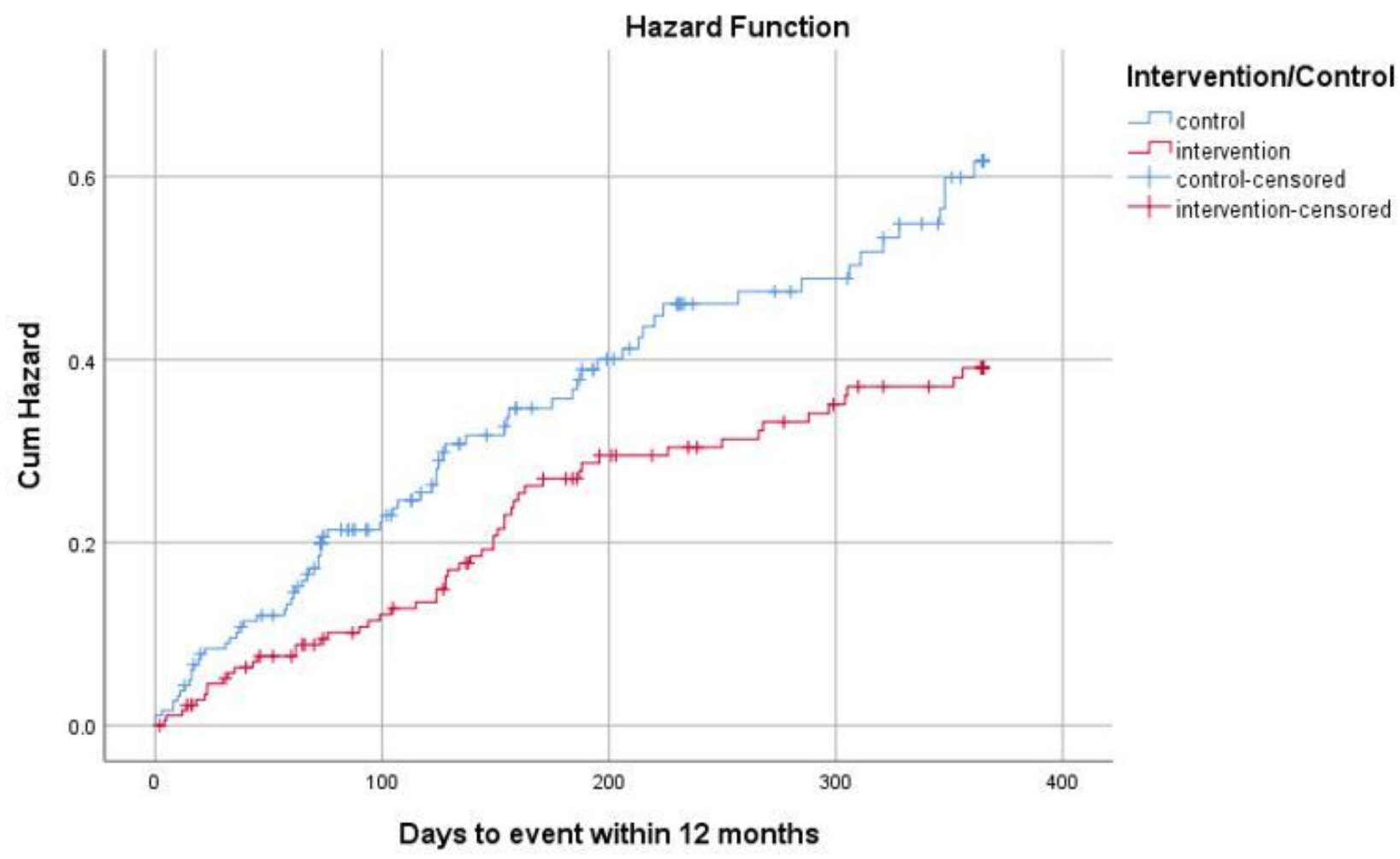

Figure 3

Kaplan Meier curve for days to first hospital admission in intervention and control group at 12 months.

\section{Supplementary Files}

This is a list of supplementary files associated with this preprint. Click to download.

- supplement1.doc 